\title{
REFLEXÃO E FUNDAMENTO: SOBRE A RELAÇÃO ENTRE GOSTO E CONHECIMENTO NA ESTÉTICA DE KANT
}

\author{
Pedro Costa Rego* \\ pedrorego@onda.com.br
}

\begin{abstract}
RESUMO A Crítica da Faculdade do Juízo, de Kant, é primordialmente uma investigação crítica acerca de uma certa classe de juízos chamados reflexionantes, que se subdivide em dois grupos, estéticos e teleológicos, e se define em oposição a uma outra classe, a dos chamados juízos determinantes. Nosso objetivo neste artigo é elaborar a hipótese de um privilégio fundacional do juízo reflexionante estético relativamente ao conhecimento determinante. Para tanto, pretendemos cumprir duas etapas. Em primeiro lugar, procederemos a uma análise da conexão entre os temas centrais - $e$ aparentemente dissociados - do belo e da faculdade do juízo enquanto tal que justifica a passagem do projeto de uma crítica do gosto ao de uma crítica do juízo e delimita como alvo da obra o fundamento de determinação (Bestimmungsgrund) de uma "intersubjetividade" conceitualmente indeterminada. Em segundo lugar, passaremos à análise da relação entre a reflexão e o princípio da finalidade da natureza, com base na Introdução da terceira Crítica, a fim de identificar, na formulação "prática" do princípio do gosto, o germe de uma anterioridade que subordina a determinação à reflexão estética.
\end{abstract}

Palavras-chave Reflexão, Finalidade, Juízo de Gosto, Faculdade do Juízo

* Professor do Departamento de Filosofia da Universidade Federal do Paraná. Artigo recebido em 15/09/05 e aprovado em 15/11/05.

KRITERION, Belo Horizonte, ${ }^{\circ}$ 112, Dez/2005, p. 214-228 
ABSTRACT Kant's Critique of Judgment is chiefly a critical investigation into a certain class of judgments identified as "reflective", divided into the aesthetic and the teleological sub-classes and defined in opposition to those termed by Kant "determinant judgments". In this paper I intend to elaborate, in two expositive moments, the hypothesis of a foundational primacy of reflective aesthetic judgment over determinant knowledge. Firstly, I analyse the connection between the main themes - apparently dissociated - of beautiful and faculty of judgment in order to disclose both the ground of Kant's move from a Critique of Taste into a Critique of Judgment and the determining ground of a conceptually indeterminate intersubjectivity considered as the main aim of the work. In the next step I investigate the relationship between reflection and the principle of finality of nature on the basis of third Critique's Introduction in order to verify, through the "practical formula" of the principle of taste, the accuracy of the thesis supporting the primacy of aesthetic reflection over determination.

Keywords Reflection, Finality, Judgment of Taste, Faculty of Judgment

Nosso objetivo neste artigo é elaborar, a partir de uma reflexão acerca de temas essenciais da primeira parte da Crítica da Faculdade do Juízo de Kant, a hipótese de um privilégio fundacional do juízo reflexionante estético relativamente ao conhecimento determinante. Para tanto, pretendemos cumprir duas etapas. Na primeira, procederemos a uma análise da conexão entre os temas centrais - e aparentemente dissociados — do belo e da faculdade do juízo enquanto tal, que justifica a passagem do projeto de uma crítica do gosto ao de uma crítica do juízo e delimita como alvo da obra o fundamento de determinação (Bestimmungsgrund) de uma "intersubjetividade" conceitualmente indeterminada. Em segundo lugar, passaremos à análise da relação entre a reflexão e o princípio da finalidade da natureza, com base na Introdução da terceira Crítica, a fim de identificar, na formulação "prática" do princípio do gosto, o germe de uma anterioridade que subordina a determinação à reflexão estética. 
A terceira Crítica de Kant é simultaneamente uma crítica de nosso poder de julgar e uma obra de estética que trata, em sua parte principal, ${ }^{1}$ da apreciação e da criação do belo. Registre-se, não são dois temas elaborados em duas seções. ${ }^{2} \mathrm{O}$ caminho pelo qual a obra realiza uma investigação crítica de nossa faculdade de julgar em geral é o do privilégio do tema da estética, assim como o modo possível e pertinente, para Kant, de falar do belo é perguntando por juízos sobre o belo e, em seguida, pelo nosso poder de produzir juízos em geral. Pergunta-se, então: o que torna essa dupla análise uma análise tematicamente una? Qual é o tema da terceira Crítica, que unifica o belo e o poder de julgar enquanto tal e exige que a investigação de um se dê pela via da análise do outro?

O objeto de investigação da parte principal da terceira Crítica é o problema de uma certa universalidade - e, notadamente, daquilo de onde ela provém - enraizada no elemento da subjetividade transcendental, que não é fundada e circunscrita por princípios objetivos. Ao sujeito pertence necessária e constitutivamente um poder de se relacionar com objetos no modo de um tipo

1 Remetemos, aqui, exclusivamente ao testemunho da letra de Kant, na Introdução definitiva da Crítica da Faculdade do Juízo. A "Crítica da Faculdade do Juízo Teleológica", segunda parte da obra, não é menos importante do que a "Crítica da Faculdade do Juízo Estética". Ela apenas não oferece privilegiadamente uma análise da [aceito] faculdade do juízo enquanto tal. E isso porque, ainda que atue subsumindo sob o princípio supremo da faculdade do juízo reflexionante em geral, a saber, o princípio da Zweckmässigkeit, ela "procede segundo conceitos, como no conhecimento teórico (nach Begriffen verfährt, wie überall im theoretischen Erkenntnisse)". Subordinada aos princípios pertencentes à Erkenntnisvermögen, a Urteilskraft teleológica não pode gozar do estatuto de objeto privilegiado de uma Crítica que se distingue da primeira, sobretudo por tratar do poder de julgar enquanto tal, e não da sua aplicação no conhecimento objetivo e conceitual. Por isso, a posição de Kant é a de que ao menos "segundo sua aplicação, pertence ela [a faculdade do juízo teleológica] à parte teórica da filosofia" " "ihrer Anwendung nach, gehört sie [die teleologische Urteilskraft] zum theoretischen Teile der Philosophie") —à qual parte a Urteilskraft estética é completamente estranha, na medida em que, ao referir seu objeto ao princípio da finalidade formal da natureza, é a única que subsume sob um princípio "que a faculdade do juízo põe completamente a priori na base de sua reflexão sobre a natureza" ("welche die Urteilskraft völlig a priori ihrer Reflexion über die Natur zum Grunde legf'). Subsumir esteticamente sob formale Zweckmässigkeit, e não teleologicamente sob objektive Zweckmässigkeit é portanto subtrair-se à esfera de sujeição dos conceitos de objetos e credenciar-se ao estatuto de tema principal de uma obra crítica acerca do poder de julgar enquanto tal. Cf. KANT, I. Werke in zehn Bänden. Hrsg. Wilhelm Weischedel. Darmstadt, Wissenschaftliche Buchgesellschaft, 1983, Band 8; Kritik der Urteilskraft (doravante citada como CJ), Int., v. III, p. 268-270. Para uma reflexão mais detida acerca desse ponto, cf. nota 8.

2 Registre-se: a correspondência de Kant permite-nos afirmar com segurança que, ao menos até 1788-1789, o esboço da obra em questão é o de uma Crítica do Gosto. Mas à virada de uma Kritik des Geschmacks para uma Kritik der Urteilskraft não corresponde nem uma desqualificação do problema do gosto nem a decisão por um projeto de justaposição de temas desconexos. O que mobiliza a passagem é a evidência de uma coerência interna que faz do juízo reflexionante estético uma privilegiada via de acesso ao poder de julgar como tal, a essa faculdade que em juízos determinantes teóricos, práticos e em juízos estéticos empíricos renuncia, de certa forma, à sua própria autonomia judicativa. É o que será visto. Sobre a correspondência de Kant, cf. Kant's gesammelte Schriften. Preussische Akademie der Wissenschaften. Berlin: Walter de Gruyter, 1942, X, p. 505 (Carta a Reinhold, 7 de março de 1788). 
de ajuizamento cujo fundamento de determinação, apesar de universalmente válido e, portanto, universalmente comunicável, não garante para essa relação o estatuto da objetividade por se tratar ele de um princípio conceitualmente indeterminado. A investigação de tal universalidade subjetiva se traduz como crítica da faculdade de julgar no mesmo movimento pelo qual a ela pertence a Estética kantiana como pergunta pelo juízo de gosto sobre o belo. A questão preliminar que se impõe é portanto a de esclarecer o modo como se estabelecem essas duas relações. 1) A relação entre universalidade judicativa subjetiva e a Estética kantiana e 2) a relação entre universalidade judicativa subjetiva e faculdade de julgar (Urteilskraft), tomadas em conjunto, revelam a relação entre a faculdade do juízo como tal e o juízo de gosto. Em suma, explicam por que a crítica da Urteilskraft é fundamentalmente uma Estética. Seja, então, a primeira relação mencionada.

A terceira Crítica parte da constatação — exposta no livro inicial da seção que abre a primeira parte da obra, intitulado "Analítica do Belo" — de que um certo uso judicativo supõe determinadas condições que não são as mesmas que fundam nossos juízos objetivos e a maioria dos nossos juízos subjetivos. Por juízos objetivos entende Kant, até sua investigação na terceira Crítica, juízos de validade universal. Objetividade e universalidade se confundem na medida em que 1) um juízo objetivo é um juízo fundado em conceitos do entendimento ou da razão; 2) as categorias, como formas de conceitos empíricos, e as idéias da razão são elementos pertencentes à subjetividade como tal; 3) juízos que têm como fundamento de determinação princípios pertencentes a priori à subjetividade são válidos para todos os sujeitos. Que todo juízo objetivo seja universal, isso jamais será problema para Kant. O que, entretanto, a análise do gosto revelará impreciso será a formulação completa até então válida para a relação entre a objetividade e a universalidade do juízo: a saber, que universalidade seja condição necessária e suficiente para a objetividade de um juízo.

Por juízos subjetivos entende Kant, também até a terceira Crítica, juízos de validade meramente privada. Subjetivismo e validade privada confundemse na medida em que 1) um juízo subjetivo tem como fundamento de determinação (Bestimmungsgrund) uma inclinação do sujeito — isto é, a representação de um fim através do qual a razão, a serviço da inclinação, determina a faculdade da apetição (Begehrungsvermögen) do sujeito; 2) fins determinados sob a influência das inclinações jamais podem ser considerados elementos pertencentes à subjetividade como tal; e 3) juízos fundados em princípios que só contingentemente pertencem ao sujeito podem ser válidos apenas para sujeitos particulares. Jamais, para Kant, haverá problema em relação 
à classificação dos juízo de validade privada como subjetivos. Mas o que a análise do gosto revelará impreciso é a formulação completa até então válida para a relação entre subjetivismo e validade privada do juízo: a saber, que o subjetivismo seja uma condição necessária e suficiente para que a um juízo seja atribuída uma validade meramente privada.

Kant identifica no uso judicativo do predicado "belo" determinadas condições que, podendo ser expostas e deduzidas, provam que: 1) universalidade é uma condição necessária, mas não suficiente, para garantir a objetividade de um juízo e 2) subjetivismo é uma condição necessária, mas não suficiente, para condenar um juízo a uma validade meramente privada. "A Analítica do Belo" expõe comparativamente as características de um juízo que, se for o que parece ser, é universal sem ser objetivo e é subjetivo sem ser privado. Se tudo se confirmar, universalidade e subjetivismo não são mais incompatíveis. Que tudo se confirme significa: que uma dedução seja capaz de fundamentar a exposta e analisada reivindicação de universalidade de um juízo que não se funda em conceitos objetivos, mas em um sentimento de prazer. Fundamentar a pretensão de universalidade erguida pelo uso habitual do predicado "belo" é indicar no elemento da subjetividade como tal o fundamento de determinação não-objetivo de tal uso judicativo. Se isso não for possível, o juízo de gosto não se diferencia do juízo de agradabilidade privada e não há argumento contra a tese do empirismo estético. Se for possível, não é mais preciso aderir à insensatez racionalista de um gosto lógico e demonstrável para mostrar que os prazeres estéticos não são todos iguais. Em suma, a relação entre universalidade subjetiva e juízo de gosto é uma relação reivindicada. A "Analítica da Faculdade do Juízo Estética" é uma exposição da reivindicação de universalidade subjetiva que apenas o juízo de gosto ergue e uma dedução do direito do uso dessa reivindicação.

Clara a relação entre juízo de gosto e validade universal subjetiva, passamos à segunda relação mencionada. Como se explica que essa universalidade, desvendada privilegiadamente pela via de uma Estética, diga respeito tão intimamente à faculdade do juízo como tal, a ponto de a terceira Crítica não se chamar nem "crítica do juízo de gosto", nem "crítica da universalidade subjetiva", mas sim "crítica da faculdade do juízo"?

Acreditamos que a resposta se formula nos seguintes termos: Kant intenta sustentar a pretensão de universalidade erguida pelo juízo de gosto mostrando que há um fundamento intersubjetivo para um certo tipo de juízo estético e que esse fundamento é justamente a própria faculdade do juízo (Urteilskraft). O juízo de gosto sobre o belo teria essa particularidade relativamente aos juízos objetivos e estéticos empíricos: a saber, que nele, a faculdade do juízo não 
atua apenas como poder de ligação de representações, mas também como princípio, fundamento de determinação sob o qual as representações em questão são ligadas. Em outros termos, no belo, a Urteilskraft subsume sob ela mesma, e não sob um conceito do entendimento, uma idéia da razão ou a representação de um fim patológico. Subsumindo sob si como sob o poder de julgar ele mesmo (das Vermögen zu urteilen selbst), ${ }^{3}$ a Urteilskraft instaura, entre a unidade do sujeito e um conjunto de representações intuídas, um domínio de relacionamento universalmente válido que, entretanto, não envolve um processo de constituição lógica de objetos. Eis a universalidade subjetiva que interessa ao Kant da terceira Crítica: a universalidade de um juízo que tem como fundamento de determinação não um conceito, mas o poder de julgar enquanto tal. Sendo esse juízo justamente o juízo de gosto sobre o belo, fica explicada a relação entre "universalidade subjetiva", "juízo de gosto" e "faculdade do juízo", e compreende-se no mesmo movimento por que a Estética de Kant é a parte principal de uma obra chamada "crítica da faculdade de julgar" Tanto nosso poder de julgar como tal quanto a universalidade indemonstrável que ele patrocina quando não atua a serviço da razão teórica e da razão prática se oferecem privilegiadamente a uma investigação crítica, quando colocamos sob análise o juízo de gosto sobre o belo.

Isso posto, trata-se de acompanhar Kant na decomposição analítica desse juízo (o juízo de gosto) nos seus elementos constitutivos, a fim de compreender a natureza de seu fundamento de determinação e no que consiste o registro de universalidade subjetiva a que ele dá acesso. A hipótese que procuramos defender é a de que ao juízo de gosto sobre o belo, em virtude de seu fundamento de determinação e do registro de universalidade subjetiva que ele delimita, pertence um privilégio fundacional em relação aos juízos de conhecimento em geral.

3 Cf. CJ, §35, p. 381. Eis o desdobramento analítico dessa tese de Kant, esboçada no §9 e apresentada definitivamente no $\S 35$ da CJ: o juízo de gosto sobre o belo tem como princípio de subsunção uma certa afinação (Stimmung) subjetiva entre a faculdade do entendimento e a faculdade da imaginação. Essa Stimmung é caracterizada como uma condição subjetiva do uso da faculdade do juízo para um conhecimento em geral. Mas "a condição subjetiva de todos os juízos é o próprio poder de julgar (das Vermögen zu urteilen selbst), ou a faculdade do juízo (Urteilskraft)". Desse modo, é o poder de julgar enquanto tal que se faz sensível, isto é, esteticamente acessível por ocasião de uma representação a que aplicamos o predicado da beleza. A Stimmung formal e indeterminada entre a faculdade ativa dos conceitos, o entendimento, e a "faculdade das intuições" (título que merece a faculdade da imaginação na terceira Crítica, e não a da sensibilidade), "afinação" ou "disposição" vivificada no encontro com o belo, é aquilo pelo qual nos tornamos conscientes do nosso poder de ligar conceitos a intuições. Tornamo-nos assim conscientes não da consumação de um conhecimento, mas apenas do poder de julgar cognitivamente, da nossa faculdade do juízo como possibilidade de conhecimento. Em suma, no juízo de gosto, a Urteilskraft como condição subjetiva do conhecimento é o fundamento de determinação de seu próprio uso e o princípio de instauração de um registro de universalidade meramente subjetiva. 
Kant fornece na CJ basicamente três formulações para o princípio do juízo de gosto puro: chamamos "epistemológica", segundo a qual ele é uma afinação (Stimmung) subjetiva das faculdades do entendimento e da imaginação; chamamos "reflexiva", que o caracteriza como "o próprio poder de julgar ou a faculdade do juízo"; e chamamos "prática", segundo a qual ele é o princípio da finalidade (Zweckmässigkeit) formal da natureza em relação à nossa faculdade de julgar. Reservamos para outra ocasião a explicação nossos e a interessante discussão acerca do sentido de unidade dessas três formulações aparentemente dissonantes. Trabalharemos aqui fundamentalmente com a última, apresentada formalmente na Introdução definitiva da CJ e pouco elaborada ao longo da "Analítica do Belo". Acreditamos que, a partir dela, se deixa elaborar uma análise preparatória que só pode se consumar no desdobramento das acepções epistemológica e reflexiva do princípio do gosto. Em uma frase: trata-se aqui da elaboração preliminar do argumento de um privilégio fundacional do juízo de gosto sobre o belo com base em seu caráter reflexionante, decorrente da caracterização de seu fundamento como o princípio da Zweckmässigkeit. Nosso caminho será analisar a relação entre reflexão e o princípio da finalidade da natureza, com base na Introdução da terceira Crítica, a fim de identificar, na formulação "prática" do princípio do gosto, o germe de uma anterioridade que subordina a determinação à reflexão estética.

\section{II}

A terceira Crítica pronuncia-se acerca dos juízos e de nosso poder de produzi-los logo no item IV da Introdução, nos termos de uma definição: "A faculdade do juízo em geral é o poder de pensar o particular como contido sob o universal". ${ }^{4}$ A esse pensamento chama-se subsunção. O juízo como subsunção apresenta-se, ainda segundo a Introdução, em dois modos básicos, o determinante e o reflexionante, que são assim explicitados:

Se o universal (a regra, o princípio, a lei) é dado, a faculdade do juízo que nele subsume o particular é determinante (bestimmend). Porém, se só o particular for dado, para o qual ela deve encontrar o universal, então a faculdade do juízo é simplesmente reflexionante (reflektierend) ${ }^{5}$.

O critério que permite a divisão dos juízos em determinantes e reflexionantes é a presença dada de um universal. Isso significa que a falta de

4 CJ, Int., IV, p. 251.

5 Idem. 
um universal dado não impede ou descaracteriza o juízo como subsunção do particular sob um universal. Não havendo um universal "dado", pode haver juízo, a saber, apenas reflexionante e nunca determinante. Mas pergunta-se: como é possível subsumir, vale dizer, pensar um particular como contido sob um universal sem que haja um universal? Enfim, o que é um juízo reflexionante?

O texto da Introdução esclarece:

A faculdade de juízo determinante, sob leis universais transcendentais dadas pelo entendimento somente subsume. A lei lhe é indicada a priori e ela, por isso, não precisa pensar para si mesma uma lei de modo a poder subordinar o particular na natureza ao universal. (grifo nosso)

Por exclusão podemos então inferir: a faculdade do juízo reflexionante distingue-se da determinante por uma tarefa com a qual somente ela anda às voltas. Porque falta-lhe o universal sob o qual subsumir, porque faltam-lhe "leis universais transcendentais dadas pelo entendimento", 6 ela, além de subsumir, precisa pensar para si mesma uma lei que lhe permita descobrir um o universal sob o qual há de subsumir seu objeto. A faculdade do juízo reflexionante vive, assim, às voltas com uma dupla tarefa. É em virtude da primeira delas que ela se chama reflexionante, ou simplesmente nãodeterminante, justamente a tarefa de que a determinante se vê dispensada, a saber, a tarefa de pensar para si mesma uma lei. Pensada essa lei, a faculdade do juízo é conduzida para diante de princípios universais ${ }^{7}$ que antes faltavam. Agora, se eles não mais faltam, a faculdade do juízo não precisa mais refletir. A segunda tarefa, a de "subordinar o particular na natureza ao universal", encontrado pela via da reflexão, já não é mais, a rigor, uma tarefa reflexionante.

O que, então, caracteriza essencialmente a faculdade do juízo reflexionante é a mencionada lei que ela pensa para si mesma. Mas no que consiste

6 Nessa formulação inicial, Kant parece descrever a faculdade do juízo determinante como aquela que subsume, exclusivamente no registro teórico-cognitivo, sob as categorias do entendimento como princípios que contêm a regra de ligação do que os objetos são. Convém observar, entretanto, que não são apenas "leis transcendentais dadas pelo entendimento" que atuam como Bestimmungsgrund em juízos determinantes. É também determinante o juízo que subsume sob leis fornecidas pela faculdade da razão, e, em geral, sob leis que contém a regra objetiva da ligação daquilo que os objetos devem ser, vale dizer, leis práticas, e não apenas leis teóricas relativas ao que os objeto são.

7 Observe-se que os princípios universais para diante dos quais a faculdade do juízo é eventualmente conduzida pela reflexão não são aquelas "leis transcendentais dadas pelo entendimento". Quando não se esgota na sua dimensão estética, a atividade reflexionante, que é o pensamento de uma lei orientado no sentido da descoberta de universais para os particulares, conduz a faculdade do juízo para a descoberta de leis empíricas reguladoras do funcionamento específico de formas da natureza que permanecem indeterminadas em seu funcionamento e organização mesmo quando pensadas sob as categorias do entendimento. Em outras palavras, quando a reflexão alcança seu telos, a faculdade do juízo progride, pela renovada descoberta de leis empíricas particulares (subordinadas aos conceitos puros do entendimento), na direção da unidade completa da natureza como sistema. 
propriamente o juízo de uma faculdade de julgar que precisa pensar para si uma lei para poder subsumir? Vimos que, uma vez pensada a lei e, por conseguinte, descoberto o universal para um particular dado, a tarefa da faculdade do juízo é determinante; ela simplesmente subsume, visto que o universal finalmente está dado. Mas se julgar é subsumir o particular sob um universal, no que consiste julgar de modo exclusivamente reflexionante? Se ainda não há universal nenhum dado, se a faculdade do juízo reflexionante está justamente às voltas com o pensamento de uma lei para, a partir disso, descobrir um universal sob o qual subsumir, como pode ela, enquanto reflexionante, julgar? No que consiste um juízo reflexionante? Não somos levados a crer que ou bem se reflete, ou bem se julga? Como refletir pode ser, ao mesmo tempo e no mesmo sentido, julgar, de tal modo que haja um "pensamento do particular como contido sob um universal"... reflexionante?

Se reflexão, ao lado de determinação, é modalização do ato de julgar, então a faculdade do juízo reflexionante não apenas pensa uma lei e busca um universal. Ela, enquanto reflexionante, subsume. Para isso, é forçoso que ela disponha de um universal. A rigor, não existe o pensamento de um particular como contido sob um universal, isto é, um juízo, sem que haja um universal. Kant chama de princípio ou fundamento de determinação o universal sob o qual a faculdade do juízo subsume um particular. Pergunta-se: qual é o princípio ou fundamento de determinação (o universal) do juízo reflexionante, visto que, apesar da problemática definição supracitada, ele precisa ter um, de algum modo dado, se ao menos merece o estatuto de juízo?

A afirmação de que a faculdade do juízo reflexionante não dispõe de um universal dado não pode implicar que o juízo reflexionante não tenha princípio. Simplesmente, seu princípio é aquele que, na ausência de um universal dado, a faculdade do juízo pensa para si. O princípio da faculdade do juízo reflexionante é a mencionada lei que ela pensa para si mesma com vistas a ser conduzida para diante de leis empíricas do funcionamento específico de formas da natureza. Mas se "reflexionante" é uma qualificação de juízo, então, no movimento mesmo pelo qual a faculdade do juízo pensa para si uma lei, subsume ela um particular sob essa lei. O juízo reflexionante é a referência de um dado qualquer ao princípio pensado pela própria faculdade do juízo com vistas a descobrir "universais dados", isto é, lei empíricas da natureza, e subsumir certas formas específicas da natureza sob eles.

Se tudo for assim, o princípio supremo da faculdade do juízo reflexionante é uma estratégia e uma condição para a subsunção determinante. Para podermos determinar formas específicas da natureza sob determinados princípios universais, quando faltam esses princípios, precisamos refletir, isto é, pensar 
essas formas, antes de mais nada, sob um princípio que não é um universal dado, que não é uma lei empírica, mas sim uma lei que condiciona a possibilidade da descoberta de leis empíricas e juízos determinantes. Esse princípio que condiciona, de um modo ainda um tanto enigmático, a possibilidade de juízos determinantes é o princípio ou a lei que a faculdade do juízo, enquanto reflexionante, pensa para si própria e é o fundamento de determinação de juízos chamados reflexionantes em geral.

Temos portanto que, já na caracterização inicial dos juízos reflexionantes em geral, fica sugerida sua anterioridade em relação a um certo tipo de conhecimento. O conhecimento das leis empíricas da natureza depende, num certo sentido, funda-se, num certo sentido, no ato reflexionante, e, portanto, no seu princípio judicativo. É Kant quem apresenta, ainda nesse restrito domínio de tematização, um privilégio fundacional da reflexão em relação à determinação cognoscitiva. Por conseguinte, se levarmos em conta que é a faculdade do juízo estética, e não a teleológica, que paradigmaticamente responde pelo princípio da reflexão em geral, ${ }^{8}$ então podemos dizer que o

8 Sobre esse privilégio, Kant assim se pronuncia: "Numa crítica da faculdade do juízo, a parte que contém a faculdade do juízo estética é aquela que lhe é essencial, porque apenas esta contém um princípio que a faculdade do juízo coloca inteiramente a priori na sua reflexão sobre a natureza, a saber, o princípio de uma conformidade a fins formal da natureza segundo suas leis particulares (empíricas) para a nossa faculdade de conhecimento, conformidade sem a qual o entendimento não se orientaria naquelas" (CJ, Int. VIII, p. 268). Os juízos reflexionantes não têm todos a mesma natureza e os mesmos fins. Essa diversidade permite a Kant classificá-los em dois grupos: o dos estéticos e o dos teleológicos. Se a condição de reflexionante, e por conseguinte, a presença do princípio da Zweckmässigkeit e a conformidade a uma intenção cognoscitiva, não os identifica, é porque o juízo reflexionante teleológico, à diferença do estético, é um juízo de conhecimento; o juízo de conhecimento de um telos. Ele é, portanto, um juízo conceitual. A letra da Introdução assim o caracteriza: "A faculdade de juízo teleológica [...] procede, como sempre acontece no conhecimento teórico, segundo conceitos [...]. Por isso, segundo a sua aplicação, pertence à parte teórica da filosofia..." (CJ, Int., VIII, p. 270). Reflexionante e no entanto... juízo de conhecimento. Nos termos de Jacques Taminiaux, "há uma quase-objetividade nesse juízo" ("il y a une quasi-objectivité de ce jugement'), explicada pelo fato de que "o juízo reflexionante teleológico, ainda que não forneça conceito do objeto, é pelo menos orientado para a natureza..." ("jugement réfléchissant téléologique, encore qu'il ne fournisse pas de concept de l'objet, est du moins orienté sur la nature..."). (TAMINIAUX, J. La Nostalgie de la Grèce à l'Aube de l'ldéalisme Allemand. La Haye: M. Nijhoff, 1967. p. 34). Tudo indica que um mesmo juízo não pode ser ao mesmo tempo reflexionante e conceitual (supondo que aqui, a despeito de toda flutuação terminológica da CJ a esse respeito, não se trata do "conceito" da finalidade). Mas ele pode fazer da subsunção reflexionante indeterminada uma etapa da determinação funcional. Ele pode, portanto, à diferença do estético, já dispor de uma determinação conceitual da natureza do objeto julgado, e se propor a determiná-lo, com o uso da reflexão, do ponto de vista de sua função em um todo sistemático. A reflexão é, aqui, uma atividade que não tem seu fim nela mesma. Ela é um instrumento utilizado no conhecimento determinado da função de um organismo, e nesse conhecimento ela se esgota. Enquanto instrumento, a reflexão do juízo teleológico por si só não satisfaz. Refletindo para determinar, o juízo teleológico usa de reflexão a contragosto, não vê gosto algum em refletir e estaria mais à vontade na parte teórica da filosofia, ao lado daqueles juízos chamados determinantes, pelos quais "eu me decido sem rodeios pela verdade". (KANT, I. Werke in zehn Bänden. Hrsg. Wilhelm Weischedel. Darmstadt: Wissenschaftliche Buchgesellschaft, 1983. Logik - ein Handbuch zu Vorlesungen. Band 5, p. 504) É para esse sentido que apontam as considerações de Kant, na Introdução, acerca da teleologia: a Urteilskraft teleológica é aquela que "somente utiliza o conceito da finalidade para refletir sobre os produtos da natureza no respeitante à conexão dos fenômenos na natureza" (CJ, Int., p. 253), como "fio condutor de investigação da natureza" (CJ, Int., II, 
mencionado privilégio fundacional antepõe, nos limites da caracterização apresentada, o juízo de gosto ao conhecimento empírico.

Kant apresenta o princípio dos juízos reflexionantes nos seguintes termos:

Tal princípio não pode ser senão este: como leis universais da natureza têm seu fundamento em nosso entendimento, que as prescreve à natureza (ainda que somente segundo o conceito universal dela como natureza), as leis empíricas particulares, no que diz respeito àquilo que nelas é deixado indeterminado pelas leis universais da natureza, precisam ser consideradas segundo uma tal unidade <nach einer solchen Einheit betrachtet werden müssen $\rangle$, como se $\langle a l s o b\rangle$ um entendimento (ainda que não o nosso) as tivesse dado, com vistas à 〈zum Behuf〉 nossa faculdade de conhecimento para tornar possível um sistema da experiência segundo leis da natureza particulares. Não que desse modo um tal entendimento tivesse realmente que ser admitido $(\ldots)^{9}$.

Algumas linhas adiante, o princípio em questão é finalmente batizado: finalidade da natureza, conformidade a fins da natureza, Zweckmässigkeit. $\mathrm{O}$ que a faculdade do juízo, em sua versão reflexionante, precisa pensar para si mesma com vistas a superar o estágio reflexionante em que ela se encontra e se tornar determinante, isto é, "subordinar o particular na natureza ao universal", é uma tal unidade (solche Einheit). Três elementos pertencentes a esta apresentação inicial do princípio da finalidade da natureza merecem algumas considerações.

O primeiro deles é o fato de que a unidade pensada tem o aspecto de um entendimento. Ela precisa ter tal aspecto justamente porque a faculdade do juízo reflexionante reflete com vistas ao conhecimento. Se o que move sua atividade reflexionante é a perspectiva da determinação cognoscitiva, ela só pode refletir sob o pressuposto de que as múltiplas formas empíricas da natureza são acessíveis ao nosso entendimento cognoscente. Diante do fato de que elas ainda não o são, razão pela qual refletimos, reflete a faculdade do juízo sob a hipótese de que elas apenas ainda não estejam acessíveis. A hipótese de que elas ainda não estão acessíveis ao nosso entendimento é a hipótese de que elas são acessíveis e conformes ao entendimento que o nosso ainda não é, mas na

p.181/139-140. A última numeração da tradução de Rubens R. Torres Filho: Duas Introduções à Crítica do Juízo. São Paulo: lluminuras, 1995) e com vistas à "ordenação final (conforme a fins) da natureza em um sistema da experiência" (CJ, Int., V). Enfim, se da reflexão teleológica subtrairmos o seu telos, entenda-se aqui, o objetivo epistemológico com que se emprega o princípio da finalidade - e não esse princípio mesmo como um pressuposto - estaremos subtraindo o que a torna objetiva, a submete ao controle exclusivo do entendimento e a encerra na parte teórica da filosofia. Acreditamos que tudo isso nos confere o direito de considerar o juízo reflexionante estético, ou o juízo de gosto, caso paradigmático da reflexão na CJ e concentrar em torno dele o eventual privilégio que a reflexão em geral e seu fundamento de determinação apresentarem relativamente aos juízos conceitualmente determinados.

9 CJ, Int., IV, p. 253. 
direção do qual o nosso entendimento aspira. Esse entendimento não é o nosso, mas se ele não for um entendimento, superior ao nosso, referência ideal para o nosso e, portanto, hipotético, o pensamento que o põe como princípio de reflexão não servirá em nada para aquilo com vistas a que a reflexão reflete, a saber, nosso conhecimento. É somente o estatuto de "um entendimento" que torna essa unidade pensada pela faculdade do juízo reflexionante algo favorável (zum Behuf) "à nossa faculdade de conhecimento para tornar possível um sistema da experiência segundo leis da natureza particulares".

$\mathrm{O}$ segundo elemento concerne ao fato de que a unidade que a faculdade do juízo reflexionante pensa para si, sob a qual ela judicativamente subsume seus objetos e que tem o aspecto de um entendimento superior, é apresentada como a unidade de um "como se". Note-se que o princípio do juízo reflexionante não é uma unidade hipotética. Não é "como se" houvesse uma unidade judicativa, "como se" o juízo reflexionante tivesse um princípio. Ele, de fato, o tem e sob ele, de fato, subsume. O que, entretanto, caracteriza esse princípio de fato existente e atuante é que aquilo que ele de fato afirma é uma hipótese. Subsumir sob um princípio hipotético não é, aqui, subsumir sob a hipótese de que há um princípio. A rigor, esta última formulação não tem sentido, porque basta admitirmos que haja subsunção para que a presença de um princípio seja um fato e não uma hipótese. Kant explica o "como se" da Zweckmässigkeit nos seguintes termos: o princípio da finalidade é uma idéia que serve de princípio (eine Idee, die zum Prinzip dient); é um princípio subjetivo (subjektives Prinzip); é uma unidade normativa pensável, mas imperscrutável (nicht zu ergründende aber doch denkbare gesetzliche Einheit); é, finalmente, um princípio pressuposto (vorausgesetzt), admitido (angenommen), com vistas a um uso (Gebrauch) em que a faculdade do juízo nada prescreve (vorschreibt), nada acrescenta (beilegt) à natureza de modo determinante, mas apenas reflete sobre ela (zum Reflektieren, nicht zum Bestimmen). O final do item V da Introdução reúne todas essas características em torno de um termo constituído a partir da língua grega: heautonomia. O princípio da finalidade da natureza, que não é um entendimento superior mas a hipótese de um entendimento superior em relação ao qual a natureza é final, é um princípio "heautônomo" da faculdade do juízo. Isso significa: um princípio que a faculdade do juízo tira de si mesma - heautou - e confere a si mesma — heauto. Tirar de si mesma, conferir a si mesma, utilizar, admitir, servir-se de, pressupor; o "como se" da finalidade diz que a natureza na multiplicidade de suas formas pode ou bem ser conforme a um entendimento ou bem não o ser; mas diz, sobretudo, que nós teremos que nos comportar em relação a ela apostando nessa conformidade se, e somente se, estivermos comprometidos com a tarefa de 
conhecê-la exaustivamente. O princípio hipotético, heautônomo e subjetivo da finalidade da natureza é, assim, um pressuposto de cognoscibilidade. Isso só confirma a tese anteriormente proposta de que a faculdade do juízo reflexionante reflete, em princípio, por princípio, desde o princípio com vistas à determinação, com vistas a deixar de ser reflexionante, com vistas a encontrar o "universal dado" que, no momento, acidentalmente falta. Ainda que subjetivo, o princípio da finalidade é um princípio de conhecimento. ${ }^{10}$

Finalmente, o terceiro elemento dessa apresentação introdutória do princípio da finalidade merece atenção especial. Ele diz respeito à relação entre o pressuposto entendimento superior e as múltiplas formas da natureza que a reflexão a ele reporta. Há aqui algo de decisivo para a caracterização do princípio reflexionante como Zweckmässigkeit: conformidade a fins. Aqui estão contidos também, em germe, o fundamento da tese da Estética kantiana como unificação sistemática da obra crítica e a explicação mesma do caráter aprazível da beleza. $\mathrm{O}$ uso da expressão gegeben hätte indica que esse entendimento heuristicamente hipotético é hipoteticamente demiúrgico, criador. A rigor, não é apenas um entendimento; é também uma vontade superior, diríamos, um entendimento volitivo. Expliquem-se brevemente a ligação entre o geben e 1) o batismo do princípio reflexionante, 2) a tese da unidade do sistema e 3) o prazer que nos causa a reflexão sobre o belo.

10 Aqui duas objeções podem ser preliminarmente eliminadas. Não se trata, em primeiro lugar, de defender que o princípio da Zweckmässigkeité fundamento de determinação (Bestimmungsgrund) objetivo dos juízos determinantes, teóricos ou práticos, nem que o exercício da faculdade do juízo determinante depende da atividade reflexionante. Como Kant afirma, onde há determinação não há reflexão, porque não precisa haver. A atividade reflexionante é resultado de uma impossibilidade de determinação. Mas só não é necessário refletir para determinar porque e quando aquilo sobre o que a reflexão atua é um pressuposto óbvio, tácito e não tematizado para a determinação, a saber, que o objeto conhecido precisa ser conforme à estrutura categorial de nosso entendimento. Ora, o pressuposto da conformidade da natureza em relação à nossa faculdade de conhecimento só se torna visível quando aquilo que ele subjetiva e tacitamente costuma condicionar simplesmente não acontece, a saber, a determinação do múltiplo segundo conceitos de objetos. A reflexão, portanto - que se exerce sob o princípio da hipótese de um entendimento superior como imagem do pressuposto de que o mais específico na natureza é para nós mesmos cognoscível -, não é ela mesma condição da possibilidade do conhecimento. O que aqui é condição de possibilidade do conhecimento, a saber, condição subjetiva, é o pressuposto, tácito na determinação e explícito na reflexão, de cognoscibilidade da natureza em sua mais periférica nervura. Assim, a finalidade é um princípio de conhecimento na medida em que ela é a idéia heautônoma por meio da qual a faculdade do juízo, na impossibilidade da determinação, explicita nossa conviç̧ão, a despeito da falta de evidências, de que a natureza é exaustivamente cognoscível. Em segundo lugar, não convém minimizar a relação da Zweckmässigkeit ao processo cognoscitivo com base no anunciado "subjetivismo" do princípio reflexionante. A esse respeito, convém observar que o $\$ 22$ da CJ, no momento expositivo que a "Analítica do Belo" consagra ao tema da modalidade do juízo de gosto, esboça e abandona sumariamente uma discussão sobre se o princípio do juízo reflexionante estético é um princípio constitutivo ou regulativo. Que a discussão, embora explicitamente direcionada à formulação "epistemológica" do princípio do juízo de gosto (a saber, como Stimmung subjetiva de imaginação e entendimento) diga respeito diretamente à Zweckmässigkeit é algo que não pode ser demonstrado aqui. Registre-se apenas que o princípio dos juízos reflexionantes pode estar ainda mais decisivamente conectado ao conhecimento e ao esquematismo objetivo do que o que se espera de uma idéia regulativa. 
O princípio geral da reflexão, que se mostrou, antes mesmo de seu batismo e de modo ainda provisório, como fundamento da possibilidade de juízos de conhecimento empírico, chama-se Zweckmässigkeit, porque ele é o pensamento de que um entendimento superior criou as referidas formas múltiplas da natureza, potencialmente cognoscíveis de modo empírico, segundo a representação de um fim (Zweck). As formas múltiplas da natureza seriam, assim, conformes ao fim (zweckmässig) a partir de cuja representação um entendimento superior as teria intencionalmente dado. Refletir é, portanto, referir um particular ao princípio da hipótese de que uma vontade superior, determinada pela representação da existência dele como um fim a ser realizado, deu essa existência, vale dizer, o criou.

Quando se lê a terceira Crítica como uma obra orientada pela tarefa de unificar o sistema crítico, a vocação demiúrgica da representação do princípio reflexionante parece particularmente importante. Ora, o que Kant anuncia na Introdução definitiva da obra é que se trata de pensar a "passagem do domínio dos conceitos de natureza para o domínio do conceito de liberdade", ${ }^{11} \mathrm{Se}$, e em que medida, a terceira Crítica oferece essa descoberta, é uma controvérsia que não nos interessa no momento. Interessa apenas o fato de que tal passagem se torna concebível apenas quando uma manifestação particular da natureza, subordinada ao princípio necessário da causalidade natural, é vista como tendo sido dada (gegeben) a partir de uma vontade superior segundo a representação de fins, vale dizer, a partir de uma causalidade por liberdade. Se em um objeto essa conciliação se faz de algum modo efetiva, então tem-se elementos para provar que a base do princípio da finalidade da natureza sustenta a articulação sistemática dos domínios teórico e prático da filosofia crítica.

Por fim, é uma tese da terceira Crítica a subordinação do sentimento de prazer, qualquer que seja sua qualidade, ao princípio do preenchimento de uma intenção. ${ }^{12}$ Como explicar, então, que o juízo de gosto sobre o belo, fundado apenas em um certo exercício das faculdades cognoscitivas (que lhe garantem universalidade e necessidade) e simplesmente desinteressado, envolva um sentimento de prazer? É porque a predicação do belo expressa a referência de uma forma ao princípio da finalidade (formal) da natureza; é porque referimos essa forma ao princípio pressuposto e heurístico de um entendimento intencional que sua representação em um juízo gera prazer.

11 CJ, Int., II, p. 247.

12 Cf. CJ, Int., VI, p. 261. 
Com a exposição da diferença entre juízo reflexionante e juízo determinante e com a análise dos três elementos relevantes da apresentação introdutória do princípio da reflexão em geral, vale dizer, da Zweckmässigkeit, fica mais clara a relação entre reflexão e finalidade. Um primado fundacional do juízo reflexionante estético em relação ao conhecimento aqui se anunciou na anterioridade fundacional do princípio da finalidade em relação à determinação cognoscitiva. Em poucas palavras, quando o gosto reporta uma representação particular da natureza ao princípio da Zweckmässigkeit, vale dizer, à idéia heurística, heautônoma e subjetiva ( $a l s o b$ ) de que esse particular foi dado por um entendimento superior em favor das nossas faculdades de conhecimento, o prazer estético puro que aí se gera provém do encontro da subjetividade com uma condição da possibilidade do conhecimento, por enquanto, apenas do conhecimento empírico. Em que medida esse caráter fundacional se amplia e intensifica na progressão dos temas da $\mathrm{CJ},{ }^{13}$ é algo que precisa ser visto.

$13 . .$. e, acreditamos, se consuma no desdobramento da acepção propriamente epistemológica do princípio do juízo reflexionante estético (que se encontra sobretudo na base do movimento argumentativo da Dedução), tema que, infelizmente, ultrapassa o escopo desta exposição preliminar... 